\title{
The glycyl radical enzyme arylacetate decarboxylase from Olsenella scatoligenes
}

Qiang Lu $u^{1,2 \dagger}$ Yifeng $\mathrm{Wei}^{3 \dagger}$, Lianyun $\mathrm{Lin}^{1}$, Jiayi Liu ${ }^{1}$ Yongxu Duan ${ }^{1}$, Yaxin $\mathrm{Li}^{1}$, Weixiang Zhai ${ }^{4}$, Yangping Liu ${ }^{4}$, Ee Lui $\mathrm{Ang}^{3}$, Huimin Zhao ${ }^{3,5^{*}}$, Zhiguang Yuchi ${ }^{*}$, Yan Zhang ${ }^{1,2^{*}}$

${ }^{1}$ Tianjin Key Laboratory for Modern Drug Delivery \& High-Efficiency, Collaborative Innovation Center of Chemical Science and Engineering, School of Pharmaceutical Science and Technology, Tianjin University, Tianjin 300072, China.

${ }^{2}$ Frontiers Science Center for Synthetic Biology (Ministry of Education), Tianjin University, Tianjin 300072, China.

${ }^{3}$ Singapore Institute of Food and Biotechnology Innovation, Agency for Science, Technology and Research (A*STAR), Singapore, 138669, Singapore.

${ }^{4}$ Tianjin Key Laboratory on Technologies Enabling Development of Clinical Therapeutics and Diagnostics, School of Pharmacy, Tianjin Medical University, Tianjin 300070, China.

${ }^{5}$ Department of Chemical and Biomolecular Engineering, University of Illinois at Urbana-Champaign, 600

South Mathews Avenue, Urbana, Illinois 61801, USA.

* To whom correspondence should be addressed.

\section{Corresponding Authors}

Prof. Yan Zhang, Tianjin Key Laboratory for Modern Drug Delivery \& High-Efficiency, Collaborative Innovation Center of Chemical Science and Engineering, School of Pharmaceutical Science and Technology, Tianjin University, Tianjin, 300072, China. Phone: (86) 22-87401835. Fax: (86) 22-87401830. E-mail: yan.zhang@tju.edu.cn;

Prof. Zhiguang Yuchi, Tianjin Key Laboratory for Modern Drug Delivery \& High-Efficiency, Collaborative Innovation Center of Chemical Science and Engineering, School of Pharmaceutical Science and Technology, Tianjin University, Tianjin, 300072, China. Phone: (86) 22-27406121. Fax: (86) 22-87401830. E-mail: yuchi@tju.edu.cn;

Prof. Huimin Zhao, Department of Chemical and Biomolecular Engineering, University of Illinois at Urbana-Champaign, 600 South Mathews Avenue, Urbana, Illinois, 61801, USA. Phone: (217) 333-2631. Fax: (217) 333-5052. E-mail: zhao5@illinois.edu.

\section{Author Contributions}

$\dagger$ These authors contributed equally to this work. 


\section{Supporting Information}

\section{Materials and methods}

\section{General}

Lysogeny Broth (LB) medium was purchased from Oxoid Limited (Hampshire, UK). Acetonitrile was purchased from Concord Technology (Minnesota, USA). Formic acid was purchased from Merck (New Jersey, USA). Water used in this work was ultrapure deionized water from Millipore Direct-Q. $S$-(5'-Adenosyl)-L-methionine (SAM) was purchased from Sigma Aldrich (Saint Louis, USA). Phenol, p-cresol, p-hydroxyphenylacetic acid and substrate analogs were purchased from Heowns (Tianjin, China). Plasmids and oligonucleotide primers were synthesized by General Biosystems (Anhui, China) and TSINGKE Biological Technology (Beijing, China) respectively. Talon resin was purchased from Clontech Laboratories Inc. (California, USA). All protein purification chromatographic experiments were performed on an ÄKTA pure or ÄKTA prime plus FPLC machines equipped with appropriate columns (GE Healthcare, USA) in a $4^{\circ} \mathrm{C}$ cold cabinet. Protein concentrations were calculated from their absorption at $280 \mathrm{~nm}$ measured using a Nanodrop One (Thermo Fisher Scientific). Anaerobic experiments were conducted in a Lab2000 glovebox (Etelux) under an atmosphere of $\mathrm{N}_{2}$ with less than 5 ppm $\mathrm{O}_{2}$.

\section{Gene syntheses and cloning}

Codon-optimized gene fragments of AAD (Uniprot accession number A0A100YWM3) and AAD-AE (Uniport accession number A0A100YWL0) were synthesized by General Biosystems Inc. (Anhui, China) and inserted into pET-28a-HT and pET-28a-HMT vector at the $S s p$ I restriction site respectively, using the Gibson assembly cloning protocol (New England Biolabs, Ipwich, MA, USA). The resulting plasmid HT-AAD contains in tandem: a His6-tag and a Tobacco Etch Virus (TEV) protease cleavage site followed by the construct of interest, while HMT-AAD-AE contains, in addition, maltose-binding protein (MBP) between His6-tag and TEV cleavage site to increase solubility.

\section{Expression and purification}

Escherichia coli BL21 (DE3) cells (NEB) were transformed with the plasmid HT-AAD or HMT-AAD-AE and the transformants were selected on LB agar plate supplemented with 50 $\mu \mathrm{g} / \mathrm{mL}$ kanamycin. Transformants were grown in LB medium (typically $800 \mathrm{~mL}$ in a $2.6 \mathrm{~L}$ flask) at $37^{\circ} \mathrm{C}$ in a shaking incubator at $220 \mathrm{rpm}$ after $4 \mathrm{~mL}$ pre-culture. When OD 600 reached $\sim 0.8$, the temperature was decreased to $18^{\circ} \mathrm{C}$ and isopropyl $\beta$-D-1-thiogalactopyranoside (IPTG) was added to a final concentration of $0.3 \mathrm{mM}$ to induce protein expression. After 16 $\mathrm{h}$, cells were harvested by centrifugation $\left(8000 \times \mathrm{g}\right.$ for $10 \mathrm{~min}$ at $\left.4{ }^{\circ} \mathrm{C}\right)$.

For preparation of enzymes used in activity assays, cells ( $\sim 3 \mathrm{~g}$ wet weight) were resuspended in $30 \mathrm{~mL}$ of lysis buffer $[50 \mathrm{mM}$ Tris- $\mathrm{HCl}, \mathrm{pH} 8.0,200 \mathrm{mM} \mathrm{KCl}, 1 \mathrm{mM}$ phenylmethanesulfonyl fluoride (PMSF), $0.2 \mathrm{mg} / \mathrm{mL}$ lysozyme, $0.03 \%$ Triton X-100, and 25 $\mu \mathrm{g} / \mathrm{mL}$ of DNase I (Roche, Germany)]. The cell suspension was frozen in a $-80{ }^{\circ} \mathrm{C}$ freezer, and then thawed and incubated at $25^{\circ} \mathrm{C}$ to complete lysis. Then, final concentration of $1 \%$ streptomycin sulfate and $5 \mathrm{mM} \beta$-mercaptoethanol (BME) were added to the cell lysate followed by centrifugation $\left(20,000 \times g\right.$ for $10 \mathrm{~min}$ at $\left.4{ }^{\circ} \mathrm{C}\right)$ to remove cell debris and nucleic acid. The supernatant was filtered through a $0.45 \mu \mathrm{m}$ filter and loaded onto a $5 \mathrm{~mL}$ TALON column pre-equilibrated with buffer A $(20 \mathrm{mM}$ Tris-HCl, pH 7.5, and $200 \mathrm{mM} \mathrm{KCl})$. The column was washed with 10 column volumes $(\mathrm{CV})$ of buffer $\mathrm{A}$ and then the protein was eluted with $5 \mathrm{CV}$ of buffer A containing $150 \mathrm{mM}$ imidazole and $5 \mathrm{mM}$ BME. The eluted 
protein was precipitated with solid $\left(\mathrm{NH}_{4}\right)_{2} \mathrm{SO}_{4}$ to $70 \%$ saturation and isolated by centrifugation $\left(20,000 \times \mathrm{g}\right.$ for $10 \mathrm{~min}$ at $\left.4{ }^{\circ} \mathrm{C}\right)$. The pellet was dissolved in $4 \mathrm{~mL}$ of buffer A containing $5 \mathrm{mM}$ BME and desalted using a G25 column (GE, USA, thermostat jacket tube XK16/20, packed $15 \mathrm{~cm} \times 2 \mathrm{~cm}^{2}, 30 \mathrm{~mL}$ ), pre-equilibrated with the same buffer. The eluted proteins were concentrated to $\sim 1 \mathrm{~mL}$ by ultrafiltration (Sartorius VIVASPIN TURBO 15 (30,000 MWCO, Germany)). Glycerol was added to a final concentration of $10 \%$, and the protein solutions were frozen in aliquots with liquid nitrogen, and stored at $-80{ }^{\circ} \mathrm{C}$ for further use. The purified HT-AAD $\left(\varepsilon_{280}=161,580 \mathrm{M}^{-1} \mathrm{~cm}^{-1}\right)$ and MBP-AAD-AE $\left(\varepsilon 280=87,780 \mathrm{M}^{-1}\right.$ $\mathrm{cm}^{-1}$ ) were examined on a $10 \%$ SDS-PAGE gel.

For preparation of protein material used in crystallization, cells expressing HT-AAD $(\sim 12 \mathrm{~g}$ wet weight, from $3 \mathrm{~L}$ culture) were resuspended in $120 \mathrm{~mL}$ lysis buffer [ $50 \mathrm{mM}$ Tris- $\mathrm{HCl}$, pH 8.0, $200 \mathrm{mM} \mathrm{KCl}, 1 \mathrm{mM}$ phenylmethanesulfonyl fluoride (PMSF), 0.03\% Triton X-100, and Protease Inhibitor Cocktail (Sigma catalog \# P8340)]. After lysis by probe sonication, cell debris was removed by centrifugation $\left(20,000 \times g\right.$ for $10 \mathrm{~min}$ at $\left.4{ }^{\circ} \mathrm{C}\right)$. The supernatant was filtered through a $0.45 \mu \mathrm{m}$ filter and loaded onto a $10 \mathrm{~mL}$ TALON column pre-equilibrated with buffer $\mathrm{A}$ and then the protein was eluted with $5 \mathrm{CV}$ of buffer A containing $150 \mathrm{mM}$ imidazole. The eluted fractions containing HT-AAD were pooled, TEV protease was added (TEV/HT-AAD 1:20 molar ratio), and the mixture was immediately dialyzed overnight in $4 \mathrm{~L}$ buffer A with $5 \mathrm{mM} \mathrm{BME}$, to remove imidazole. The dialyzed protein was loaded onto a 10 $\mathrm{mL}$ TALON column to retain TEV protease and the cleaved His6-tag. The flow-through containing untagged AAD was collected and dialyzed against $2 \mathrm{~L}$ buffer $\mathrm{B}(20 \mathrm{mM}$ Tris- $\mathrm{HCl}$, $\mathrm{pH}$ 8.0, $5 \mathrm{mM} \mathrm{BME)}$ for $4 \mathrm{~h}$. The protein solution was then loaded onto a $10 \mathrm{~mL}$ anion exchange Q column, washed with $400 \mathrm{~mL}$ salt gradient in buffer B (100 to $500 \mathrm{mM} \mathrm{KCl}$ ). The fraction containing AAD eluted near conductivity of $28.97 \mathrm{~ms} / \mathrm{cm}$ was concentrated to a volume of less than $5 \mathrm{~mL}$ by ultrafiltration and then injected to a Superdex 200 gel filtration column $(\sim 300 \mathrm{~mL})$ and eluted with buffer C (20 mM Tris- $\mathrm{HCl}, \mathrm{pH} 7.5,200 \mathrm{mM} \mathrm{KCl}, 1 \mathrm{mM}$ DTT (dithiothreitol)). The eluate containing AAD was collected and concentrated, followed by buffer-exchange with the storage buffer (10 mM HEPES (4-(2-hydroxyerhyl)piperazine-1ethanesulfonic acid), $\mathrm{pH}$ 7.4, $50 \mathrm{mM} \mathrm{KCl}, 1 \mathrm{mM}$ TCEP (tris(2-carboxyethyl)phosphine) using a centrifugal concentrator to $12.5 \mathrm{mg} / \mathrm{mL}$. The purified protein was examined on a $10 \%$ SDS-PAGE gel.

\section{Reconstitution and characterization of AAD-AE [Fe-S] clusters}

A solution of AAD-AE $(70 \mu \mathrm{M})$ was degassed on a Schlenk line with argon and brought into the glovebox. The reconstitution buffer contained $100 \mathrm{mM}$ Tris- $\mathrm{HCl}, \mathrm{pH}$ 7.5, $10 \mathrm{mM}$ DTT, 12 eq. ferrous ammonium sulfate and sodium sulfide. The mixture was incubated at $4{ }^{\circ} \mathrm{C}$ in an incubator (Dry Bath H2O3-100C; Coyote Bioscience, Beijing, China) overnight. A solution of EDTA (12 eq.) was added, followed by buffer exchange by repeated concentration with a centrifugal filter unit (1.5 mL Ym-30 Amicon; Millipore), and dilution with exchange buffer (20 mM Tris-HCl, pH 7.5 and $100 \mathrm{mM} \mathrm{KCl).}$

The iron contents of as-isolated and reconstituted AAD-AE were determined using ferrozine (3-(2-pyridyl)-5,6-diphenyl-1,2,4-triazine- $p, p^{\prime}$-disulfonic acid monosodium salt), according to previously reported protocol ${ }^{1}$. The standard curve was established in the range of $0-600 \mu \mathrm{M}$ Iron Standard for AAS (TraceCERT ${ }^{\circledR}$, Fluka catalogue \#16596). For this assay, $50 \mu \mathrm{L}$ of protein sample $(70 \mu \mathrm{M})$ was mixed with $100 \mu \mathrm{L}$ of $2 \mathrm{M} \mathrm{HCl}$ and incubated in a boiling water bath for $10 \mathrm{~min}$, then centrifuged for $5 \mathrm{~min}$ to remove the precipitated protein. After cooling to room temperature $(\mathrm{RT})$, saturated ammonium acetate $(150 \mu \mathrm{L})$, freshly prepared $10 \mathrm{mM}$ sodium ascorbate $(150 \mu \mathrm{L})$, and $10 \mathrm{mM}$ ferrozine $(200 \mu \mathrm{L})$ were added. Two hundred 
microlitres of the mixture was transferred to a 96-well plate and A562nm was monitored with a plate reader (Tecan M200, Switzerland) and the reading was referred to the standard curve for iron quantitation. The sulfide contents of as-isolated and reconstituted AAD-AE were determined by measuring the absorbance of methylene blue formed upon reaction with $N, N$ dimethyl-p-phenylenediamine dihydrochloride (DPD) ${ }^{2}$. The purity of AAD-AE was estimated to be $60 \%$ based on densitometry analysis of the Coomassie-stained SDS-PAGE gel using the software Image J and used to estimate the Fe and S contents per AAD-AE monomer.

To obtain the UV-Vis absorption spectra, a solution of reconstituted AAD-AE was diluted to $20 \mu \mathrm{M}$ with exchange buffer and transferred into a cuvette (Starna Cells, Quartz Septum Cell) in the glovebox. Absorption spectra were acquired in the 200-800 nm range using a Nanophotometer NP80 Mobile (Germany). For the reduced form of AAD-AE, 10 eq. of Ti (III) citrate was added and incubated for 10 min prior to absorbance measurement. Correcting for the $60 \%$ purity of AAD-AE, the extinction coefficient of the reconstituted AAD-AE [4Fe$4 \mathrm{~S}$ ] clusters was estimated to be $29 \mathrm{mM}^{-1} \mathrm{~cm}^{-1}$. Given the approximate $8410 \mathrm{~nm}$ of $15 \mathrm{mM}^{-1}$ $\mathrm{cm}^{-1}$ per cluster, we estimate that approximately 1.9 [4Fe-4S] clusters per monomer were reconstituted, consistent with the measured $\mathrm{Fe}$ and $\mathrm{S}$ contents.

\section{LC-MS assays for SAM cleavage by AAD-AE}

Detection of AAD-AE-catalyzed SAM cleavage and product formation by LC-MS was carried out as below. A reaction mixture ( $400 \mu \mathrm{L}$ total volume) containing $20 \mathrm{mM}$ Tris/ $\mathrm{HCl}$, $\mathrm{pH} 7.5,100 \mathrm{mM} \mathrm{KCl}, 400 \mu \mathrm{M}$ Ti(III) citrate, $1 \mathrm{mM} \mathrm{SAM}$ and $40 \mu \mathrm{M}$ reconstituted MBPAAD-AE was incubated overnight at RT in the glovebox. A control assay omitting Ti(III) was also performed. The reaction was quenched with formic acid (5\% v/v final concentration) and incubated in a boiling water bath for $1 \mathrm{~min}$ to denature the protein. The precipitated protein was removed by centrifugation at $14,000 \times \mathrm{g}$ for $15 \mathrm{~min}$. and the supernatant was filtered through a $0.22-\mu \mathrm{m}$ PES membrane. A $20 \mu \mathrm{L}$ portion of the supernatant was analyzed on an Agilent 6420 Triple Quadrupole LC/MS instrument (Agilent Technologies) equipped with a C18 column (Advantage ECHELON C18 $4 \mu \mathrm{m}$ 150×2.1 mm P/N: ADV8010, manufactured by ANALYTICAL). The solvent system consisted of water (A) and acetonitrile (B), and the sample was eluted with a linear gradient of $0-16 \%$ B over $30 \mathrm{~min}$, with a flow rate of $0.5 \mathrm{~mL} / \mathrm{min}$. The products were detected by UV absorption at $257 \mathrm{~nm}$, and $5^{\prime}-\mathrm{dA}$ was compared to commercial standard and verified by mass spectrometry.

\section{EPR detection of AAD glycyl radical formation}

To reconstitute the Gly• in AAD, a $250 \mu \mathrm{L}$ reaction mixture containing $20 \mathrm{mM}$ Tris- $\mathrm{HCl}$, pH 7.5, 0.1 M KCl, $40 \mu \mathrm{M}$ AAD, $80 \mu \mathrm{M}$ reconstituted AAD-AE, $1 \mathrm{mM}$ SAM, $0.1 \mathrm{mM}$ Ti(III) citrate and 5\% glycerol was incubated at RT for $10 \mathrm{~min}$ in the glovebox. Two controls omitting either Ti(III) citrate or SAM were also prepared. Samples were transferred to the EPR tubes (Wilmad Lab-Glass, 734-LPV-7), and immediately frozen in liquid $\mathrm{N}_{2}$ upon removal from the glovebox. EPR spectra were recorded using a Bruker EMX plus X-band EPR spectrometer. Data acquisition was performed with Xepr software (Bruker). The spin concentration was determined by double integration with $1 \mathrm{mM} \mathrm{CuSO}_{4}$ standard as a reference. The EPR spectra represent an average of 10 scans and were recorded under the following conditions: temperature, $90 \mathrm{~K}$; center field, $3457.75 \mathrm{Gs}$; range, $400 \mathrm{Gs}$; microwave frequency, $9.44 \mathrm{MHz}$; modulation frequency, $100 \mathrm{kHz}$; microwave power, $10 \mu \mathrm{W}$; modulation amplitude, $0.5 \mathrm{mT}$; time constant, $20.48 \mathrm{~ms}$; conversion time, $25 \mathrm{~ms}$; scan time, $20 \mathrm{~s}$; receiver gain, $30 \mathrm{~dB}$. 


\section{GC-MS quantitation of $\boldsymbol{p}$-cresol formation by AAD}

The $p$-cresol product was quantified by extraction with ethyl acetate, followed by GC-MS analysis. A standard curve was established for commercial $p$-cresol (MERYER) in the concentration range of 0.1-10 mM. Briefly, an equal volume $(300 \mu \mathrm{L})$ of ethyl acetate containing $2.0 \mathrm{mM}$ phenol (MERYER) as an internal standard was added and mixed with the samples. The organic phase was then filtered through a $0.22 \mu \mathrm{m}$ filter and subjected to GCMS analysis, performed on a Shimadzu QP2010 GC-MS system operating in ion scan mode (scan range: $\mathrm{m} / \mathrm{z} 50-700)$, and equipped with a Rxi-1ms $(30 \mathrm{~m} \times 0.25 \mathrm{~mm} \mathrm{ID} \times 0.25 \mu \mathrm{m} \mathrm{df})$ column. Helium was used as the carrier gas with a flow rate of $1.48 \mathrm{~mL} / \mathrm{min}$. The injector was operated in "splitless" mode with the injector temperature maintained at $250{ }^{\circ} \mathrm{C}$. The oven temperature for the Rxi-1ms column was ramped from 80 to $250{ }^{\circ} \mathrm{C}$ at $15{ }^{\circ} \mathrm{C}$ per min, and held 2 min. In total ion count (TIC) mode, two peaks were observed at the retention time of 8.42 and $9.82 \mathrm{~min}$, corresponding to phenol and $p$-cresol standard, respectively. The integral of the $p$-cresol TIC peak was normalized by that of phenol standard, and the standard curve was obtained by plotting the normalized integrals against the corresponding $p$-cresol concentrations.

A $300 \mu \mathrm{L}$ reaction mixture containing $20 \mathrm{mM}$ Tris- $\mathrm{HCl}, \mathrm{pH}$ 7.5, $100 \mathrm{mM} \mathrm{KCl,} 2 \mu \mathrm{M}$ AAD, 4 $\mu \mathrm{M}$ AAD-AE, $0.1 \mathrm{mM}$ Ti (III) citrate, $1 \mathrm{mM}$ SAM, and $10 \mathrm{mM} p$-hydroxyphenylacetic acid potassium salt (HPA, adjusted to $\mathrm{pH} 7.0$ with $1 \mathrm{M} \mathrm{KOH}$ ) was incubated at $30{ }^{\circ} \mathrm{C}$ for $30 \mathrm{~min}$ inside the glovebox, followed by GC-MS analysis as described above. Negative controls omitting either SAM, or AE or HPA were also prepared. The reaction product $p$-cresol eluted at the same retention time as the authentic standard, was confirmed by EI-MS (m/z) and was quantitated by referring to the standard curve. For substrate specificity assays, $5 \mathrm{mM}$ of diverse substrates analogs including the potassium salts of $o$-hydroxyphenylacetic acid ( $O$ HPA), $m$-hydroxyphenylacetic acid ( $m$-HPA), 3,4-dihydroxyphenylacetic acid (3,4-DHPA), $p$ aminophenylacetic acid ( $p$-APA), $p$-methoxyphenylacetic acid ( $p$-MPA), $p$-fluorophenylacetic acid ( $p$-FPA), 2,4,6-trifluorophenylacetic acid (2,4,6-TFPA), phenylacetic acid (PA) and indole acetic acid (IA) were tested.

\section{Determination of AAD Michaelis-Menten kinetic parameters}

For time-dependent assays, reaction mixtures containing $200 \mathrm{nM}$ AAD, $400 \mathrm{nM}$ AAD-AE, $0.1 \mathrm{mM}$ Ti(III) citrate, $1 \mathrm{mM}$ SAM and $10 \mathrm{mM}$ HPA were incubated at $30{ }^{\circ} \mathrm{C}$ inside the glovebox. Samples were removed from the glovebox at $2.5 \mathrm{~min}$ interval and exposed to air to quench the protein radical, followed by GC-MS analysis as described above. For the measurement of kinetic constants, reaction mixtures containing $50 \mathrm{nM}$ AAD, $100 \mathrm{nM}$ AADAE, $0.1 \mathrm{mM}$ Ti(III) citrate, $1 \mathrm{mM}$ SAM and varying concentrations of $\operatorname{HPA}(0.2,0.3,0.5,1.0$, 2.0, 3.0 and $5 \mathrm{mM}$ ) were incubated inside the glovebox for $10 \mathrm{~min}$ at $30^{\circ} \mathrm{C}$.

\section{Crystallization, data collection, and structure determination}

Initial screening of AAD crystals was performed using an automated liquid handling robotic system (Gryphon, Art Robbins) in 96-well format by the sitting-drop vapor diffusion method. The screens were set up at $295 \mathrm{~K}$ using various sparse matrix crystal screening kits from Hampton Research and Molecular Dimensions. Two conditions yielded protein crystals were optimized. The best condition yielding large flakelike crystals was $0.1 \mathrm{M}$ MES (2-(Nmorpholino)ethanesulfonic acid), pH 6.0, 0.2 M NaCl, 20\% w/v PEG 2000 monomethyl ether (MME), and $10 \mathrm{mM}$ HPA.

Crystals were flash cooled in liquid nitrogen using reservoir solution containing $25 \%$ glycerol as a cryoprotectant. Diffraction data were collected on BL18U1 at Shanghai Synchrotron 
Radiation Facility (SSRF) to a resolution of $3.5 \AA$. The data set was indexed, integrated, and scaled using HKL3000 suite. Molecular replacement was performed by PHENIX using a predicted structural model of AAD by Phyre 2 server $^{3}$. The structure was manually built according to the modified experimental electron density using $\operatorname{Coot}^{4}$, and further refined by PHENIX in iterative cycles ${ }^{5}$. The data collection and final refinement statistics are shown in Table S1. All structural figures were generated with UCSF Chimera.

\section{Side-directed mutagenesis}

Based on our crystal structure, G782A, C447S, H658N, S166A, K172A, W174F, Y291F, W460A, Y564F mutants predicted to affect substrate interaction and catalysis were constructed by site-directed mutagenesis using the primers listed in Table S2. Mutant proteins were purified and assayed in the same manner as the wild type version using $2 \mu \mathrm{M}$ AAD and $10 \mathrm{mM}$ HPA. Their activities were compared with that of the wild-type protein by integrating the product peak. Relative activities of these enzymes are summarized in Table 1.

\section{Sequence alignments}

MUSCLE ${ }^{6}$ was used to construct multiple sequence alignments. Sequence logos were plotted using WebLogo 7 .

\section{Growth of $O$. scatoligenes and real-time fluorescence quantitative PCR analyses}

Olsenella scatoligenes (DSM 28304) was purchased from the German Collection of Microorganisms and Cell Cultures GmbH (DSMZ, Leibniz Institute, Germany) and anaerobically cultured at $37{ }^{\circ} \mathrm{C}$ for 2 days in $5 \mathrm{~mL}$ of following media: basal Medium 104 (DSMZ) supplemented with 1) $0.5 \%$ glucose, 2) $0.5 \%$ glucose and $10 \mathrm{mM} \mathrm{HPA}, 3$ ) $0.5 \%$ glucose and $10 \mathrm{mM}$ APA, 4) $10 \mathrm{mM}$ HPA, 5) $10 \mathrm{mM}$ APA, or 6) Medium 104 omitting glucose as control. In the presence of glucose as a carbon source (media 1-3), the $\mathrm{OD}_{600}$ reached $\sim 1.5$, otherwise (in media $4-6$ ), the $\mathrm{OD}_{600}$ was $\sim 0.1$. To detect the product formation, $500 \mu \mathrm{L}$ of cultures were centrifuged at $8000 \times g$ for $10 \mathrm{~min}$. The supernatant was extracted with equal volume of ethyl acetate containing $2.0 \mathrm{mM}$ phenol as an internal standard. The upper organic phase was then subjected to GC-MS analysis after filtered through a $0.22 \mu \mathrm{m}$ filter as described above. Regardless of different cell densities in different cultures, addition of HPA and APA resulted in the formation of $\sim 9 \mathrm{mM} p$-cresol and $\sim 2 \mathrm{mM} p$-toluidine respectively. RNAs were extracted from cultures 1-3 $\left(\sim 10^{10}\right.$ cells from each culture $)$ using RNAprep pure Cell/Bacteria Kit (TIANGEN) and diluted to $500 \mathrm{ng} / \mu \mathrm{L}$. $1 \mu \mathrm{g}$ RNA was revere transcribed in a $20 \mu \mathrm{L}$ of reaction mixture containing $0.5 \mu \mathrm{g}$ random primers and the GoScript $^{\mathrm{TM}}$ Reverse Transcription System (Promega), according to the manufacturer's recommended protocol. Obtained cDNA can be frozen at $-80{ }^{\circ} \mathrm{C}$ for long-term storage. Prior to real-time fluorescence quantitative PCR (qPCR), the reverse transcriptase was inactivated at $70^{\circ} \mathrm{C}$ for $15 \mathrm{~min}$. In a typical qPCR reaction, $20 \mu \mathrm{L}$ of reaction mixture contained $4 \mu \mathrm{L}$ of 6 $\times$ diluted cDNA, $10 \mu \mathrm{M}$ gene-specific forward and reverse primers and $1 \times$ SYBR Green GoTaq ${ }^{\circledR}$ qPCR Master Mix (Promega). qPCRs were performed on a Roche LightCycle 96. The primers were designed using primer3plus (http://www.primer3plus.com) (Table S3). All reagents and consumables for the experiments were RNase-free. 
Table S1. Data collection and refinement statistics for the Olsenella scatoligenes AAD crystal (PDB ID: 7E7L)

\begin{tabular}{ll}
\hline Data collection & \\
\hline Wavelength $(\AA)$ & 0.9795 \\
Diffraction source & SSRF BEAMLINE BL18U1 \\
Detector & DECTRIS PILATUS3 6M \\
Space group & C 2 221 \\
Cell dimensions & \\
a, b, c $(\AA)$ & $85.946,225.548,234.679$ \\
$\alpha, \beta, \gamma\left({ }^{\circ}\right)$ & $90,90,90$ \\
Unique reflections & $28905(2555)^{*}$ \\
Resolution & $32.14-3.498(3.623-3.498)^{*}$ \\
$\mathrm{R}_{\text {merge }}$ & $0.221(0.786)^{*}$ \\
CC $(1 / 2)$ & $0.971(0.785)^{*}$ \\
R-pim & $0.092(0.318)^{*}$ \\
R-meas & $0.239(0.848)^{*}$ \\
AverageI/ $(I)$ & $6.3(1.8)^{*}$ \\
Completeness $(\%)$ & $98.69(93.30)^{*}$ \\
Redundancy & $6.6(7.0)^{*}$ \\
\hline Refinement & \\
\hline $\mathrm{R}_{\text {work }} / \mathrm{R}_{\text {free }}$ & $0.3056 / 0.3614$ \\
Reflections used in refinement & $27342(2287)^{*}$ \\
Average B-factor $\left(\AA^{2}\right)$ & 52.36 \\
Number of atoms & \\
Protein & 11354 \\
Ligands & 22 \\
Protein residues & 1540 \\
R.M.S.deviations & \\
RMSD length $(\AA)$ & 0.004 \\
RMSD angle $\left({ }^{\circ}\right)$ & 0.89 \\
Ramachandran favored $(\%)$ & 80.46 \\
Ramachandran allowed $(\%)$ & 13.2 \\
Ramachandran outliers $(\%)$ & 6.34 \\
Rotamer outliers $(\%)$ & 0.00
\end{tabular}

*Statistics for the highest-resolution shell are shown in parentheses. 
Table S2. Primers used for site-directed mutagenesis

\begin{tabular}{ll}
\hline Primer name & Primer sequence 5'-3' \\
\hline M166_F & GGCTATCTGACCAATACCGTGGCTGAAATGTATGCAGAAAAAGCC \\
M166_R & GGCTTTTTCTGCATACATTTCAGCCACGGTATTGGTCAGATAGCC \\
M172_F & AGTGAAATGTATGCAGAAGCAGCCTGGAATGTTCCGGAT \\
M172_R & ATCCGGAACATTCCAGGCTGCTTCTGCATACATTTCACT \\
M174_F & ATGTATGCAGAAAAAGCCTTTAATGTTCCGGATTGCGCA \\
M174_R & TGCGCAATCCGGAACATTAAAGGCTTTTTCTGCATACAT \\
M291_F & TATTGGGATACCCGCACCTTTGGTATGGGCATGGGCCG \\
M291_R & CGGCCCATGCCCATACCAAAGGTGCGGGTATCCCAATA \\
M460_F & GGTAAACAGAGCAGCGTGTTTCCGATTGTGCAGAATTAT \\
M460_F & ATAATTCTGCACAATCGGAAACACGCTGCTCTGTTTACC \\
M447_F & TAATTATGCCATTGGCGGTGCCGTGCTGCATCAGGTTCCG \\
M447_R & CGGAACCTGATGCAGCACGGCACCGCCAATGGCATAATTA \\
M564_F & CATAATGATAATACCCAGTTTATTGTTCCGGTGGGCGTT \\
M564_R & AACGCCCACCGGAACAATAAACTGGGTATTATCATTATG \\
M658_F & CATTTTGAAGTTGCACCGAATAGTATTGGCTTTCATGCA \\
M658_R & TGCATGAAAGCCAATACTATTCGGTGCAACTTCAAAATG \\
M782_F & TCTGATTGTTCGTGTTGCAGCTTATAGTGCATATTGGGCCG \\
M782_R & CGGCCCAATATGCACTATAAGCTGCAACACGAACAATCAGA \\
\hline
\end{tabular}


Table S3. Primers used for qPCR experiments

\begin{tabular}{ll}
\hline Primer name & Primer sequence 5'-3' \\
\hline F-AAD & ACCGTCTCCGAGATGTATGC \\
R-AAD & TAGCGAAGGGCAAGGTAGAA \\
F-HPAD & GACTCGAAGAGGGCGTACTG \\
R-HPAD & TCGACGACATGCTCTACGAC \\
F-AAD-MFS & CTCTTTGGTTTCGCTCCAC \\
R-AAD-MFS & GGTTCCGCTCTTATCAACCA \\
F-HPAD-MFS & GATCACCGAGAGGACCTTCA \\
R-HPAD-MFS & CCGGTCTACCTCGTGACCTA \\
F-16S rRNA & TGGTAGTCCCAGCCGTAAAC \\
R-16S rRNA & CACCTGTCTTGGCTCCTCTC \\
\hline
\end{tabular}


A

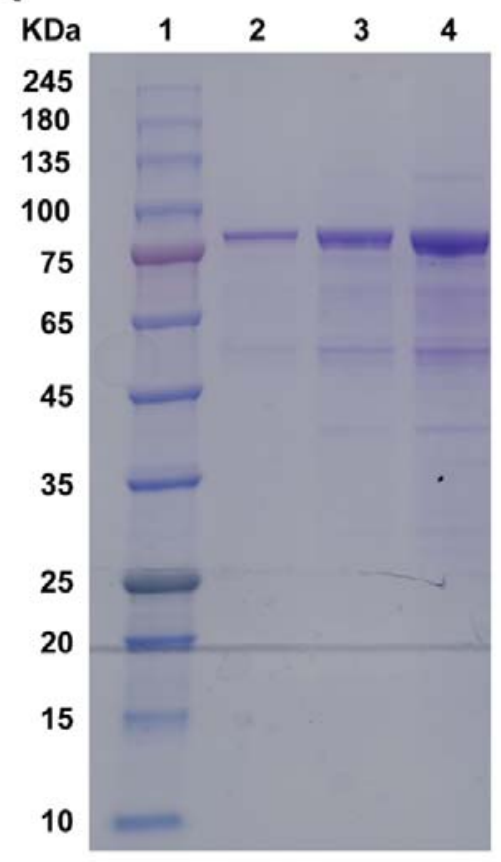

B

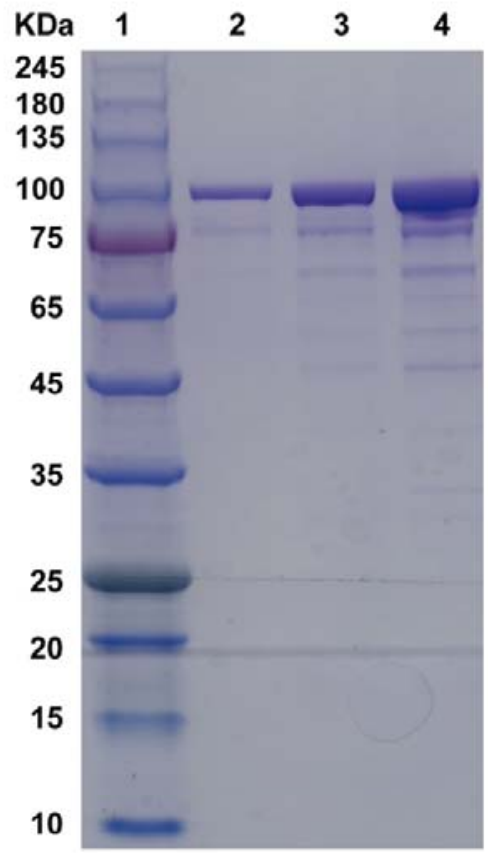

C

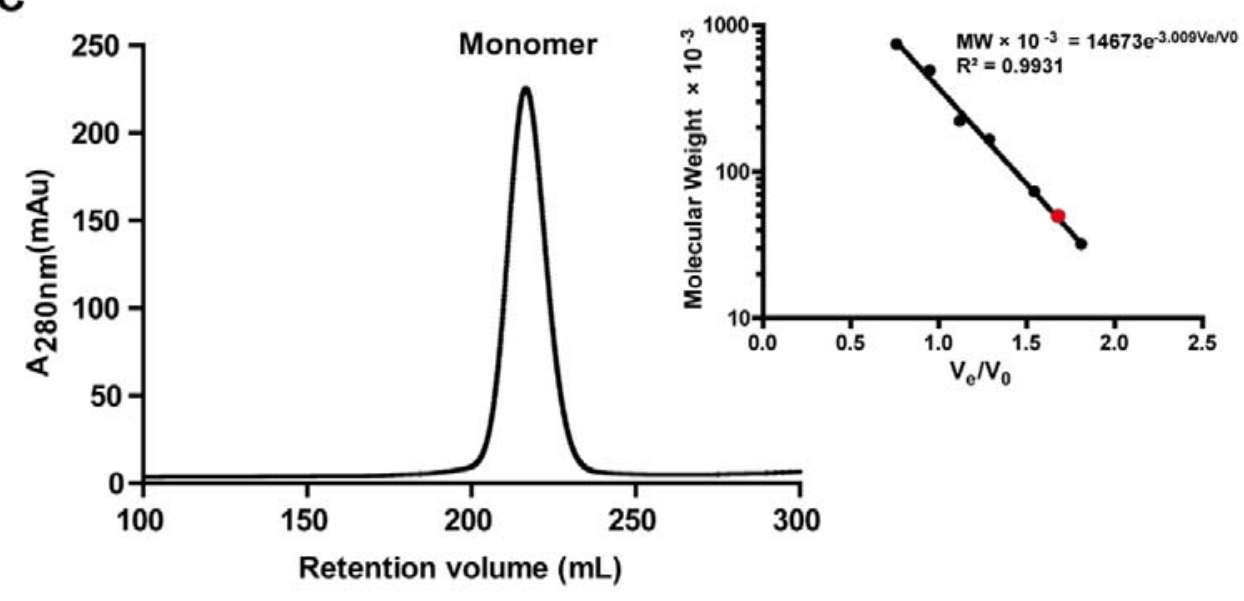

Figure S1. SDS-PAGE and SEC analyses. A. SDS-PAGE analysis of MBP-AAD-AE. B. SDS-PAGE analysis of His6-tagged AAD. $10 \%$ SDS polyacrylamide gel with: lane 1, protein molecular weight marker; and lane 2-4: 1, 2, $4 \mu \mathrm{g}$ of the purified protein. C. The AAD elution profile of Superdex 200 gel filtration chromatography. Inset: Calibration plot based on the molecular weight standards, including bovine thyroglobulin $(669 \mathrm{kDa})$, horse apoferritin $(443 \mathrm{kDa})$, sweet potato $\beta$-Amylase $(200 \mathrm{kDa})$, yeast alcohol dehydrogenase $(150$ $\mathrm{kDa}$ ), BSA (66 kDa), and bovine carbonic anhydrase (29 kDa) (Sigma MWGF 1000-1KT). 


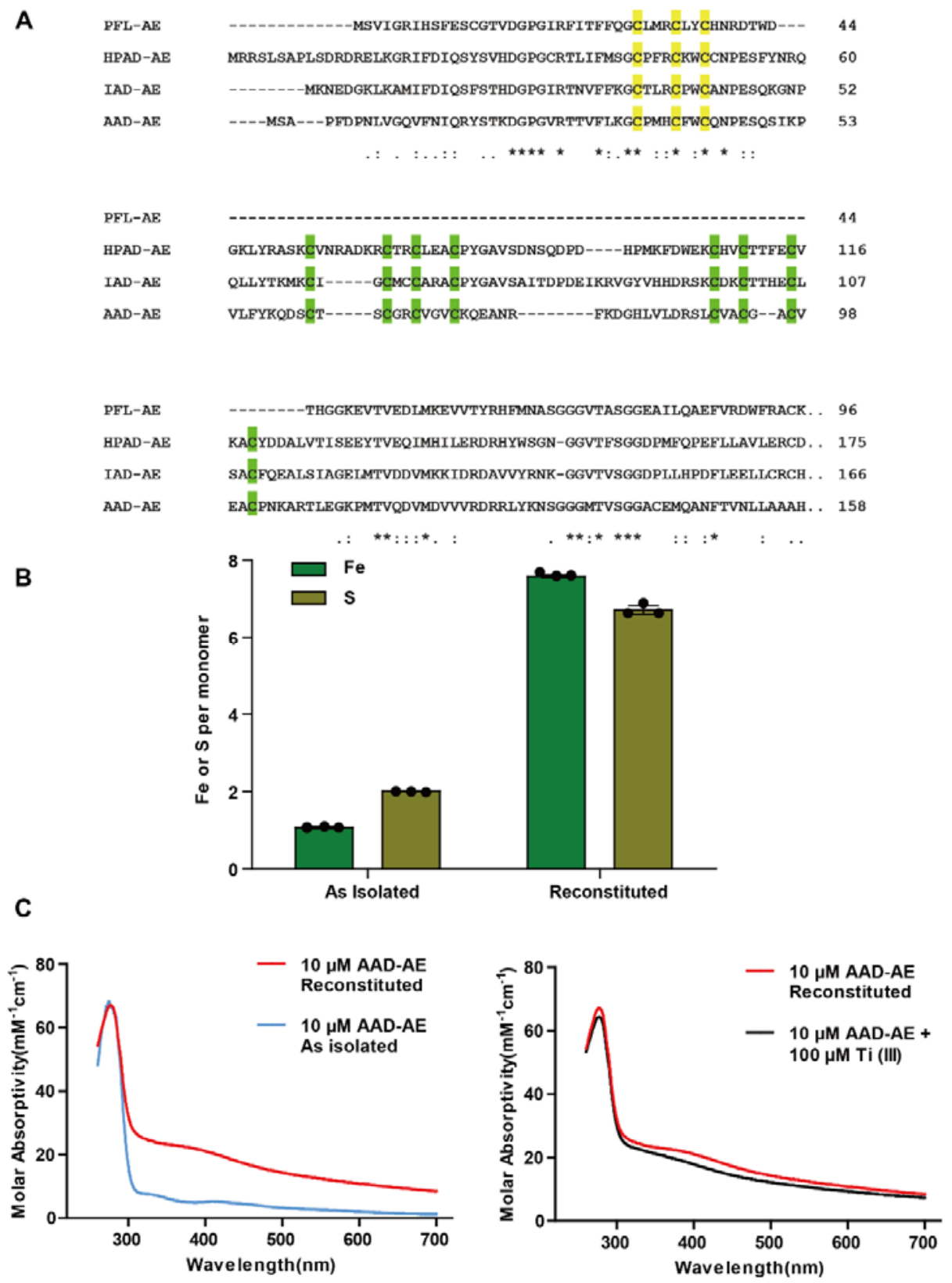

Figure S2. AE sequence alignment, [Fe-S] cluster quantitation and UV-Vis absorption spectra of AAD-AE. A. N-terminal section of the sequence alignment of selected GRE-AEs, including $E$. coli PFL-AE (UniProt P0A9N4), and $O$. scatoligenes HPAD-AE (A0A100YUP2), IAD-AE (A0A124EH39) and AAD-AE (A0A100YWL0). The three conserved Cys residues coordinating the radical SAM [4Fe-4S] cluster are highlighted yellow, and the eight Cys residues coordinating two ferredoxin domain [4Fe-4S] clusters are highlighted green. B. Fe and S contents of AAD-AE. The assays were performed in triplicate and are presented with standard deviations. Green and army bars represent Fe and S contents respectively. C. UV-Vis spectra of AAD-AE. Left, spectra of MBP-AAD-AE as isolated and reconstituted; right, spectra of reconstituted MBP-AAD-AE and its Ti(III)-reduced form. 

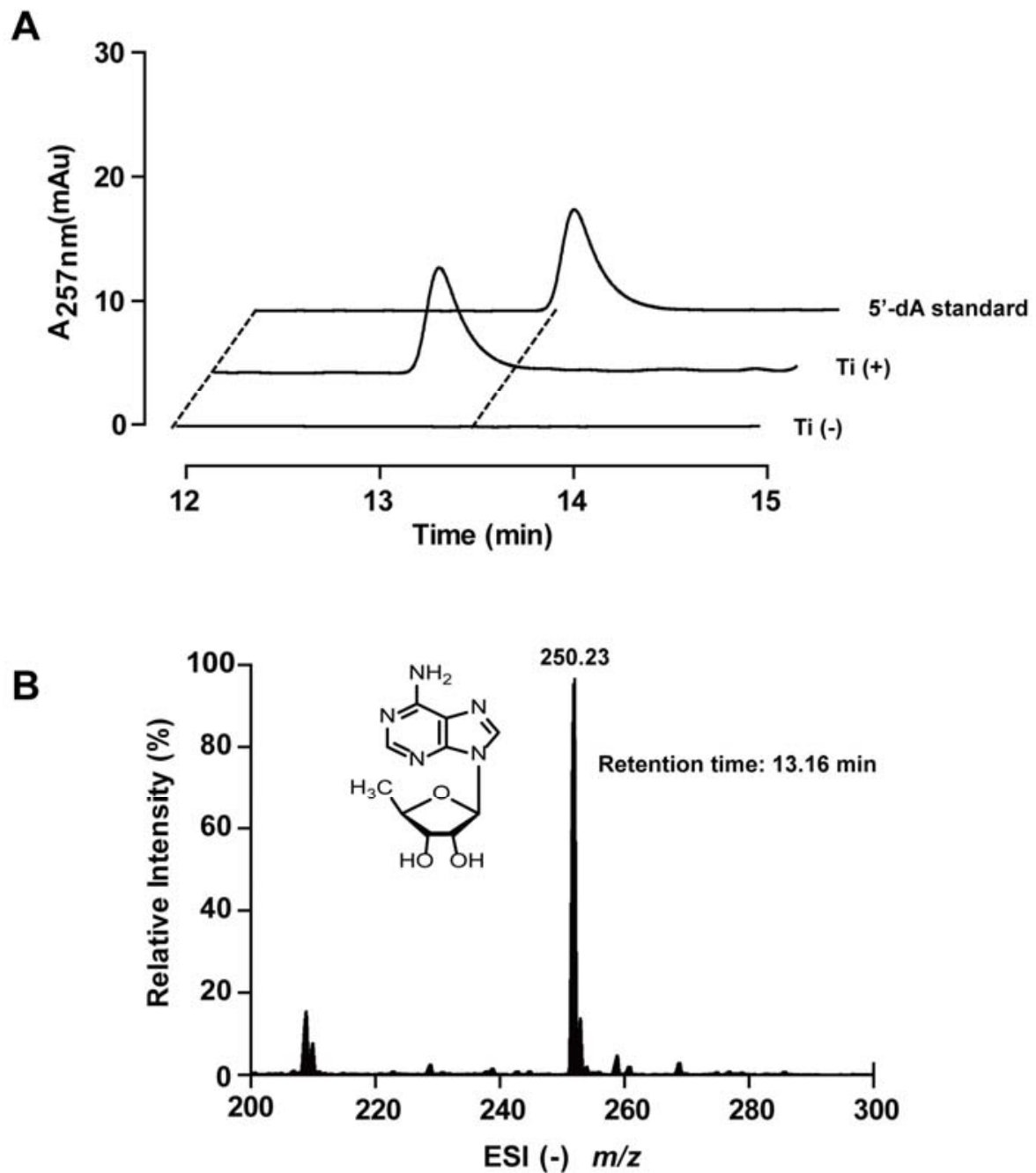

Figure S3. LC-MS analysis of 5'-deoxyadenosine (5'-dA) formation catalyzed by AADAE. A. Elution profiles of the assays in the presence and absence of Ti(III), and the commercial 5'-dA standard. B. Negative ionization mass spectrum of the 5'-dA peak in the assay eluted at $13.16 \mathrm{~min}$. 


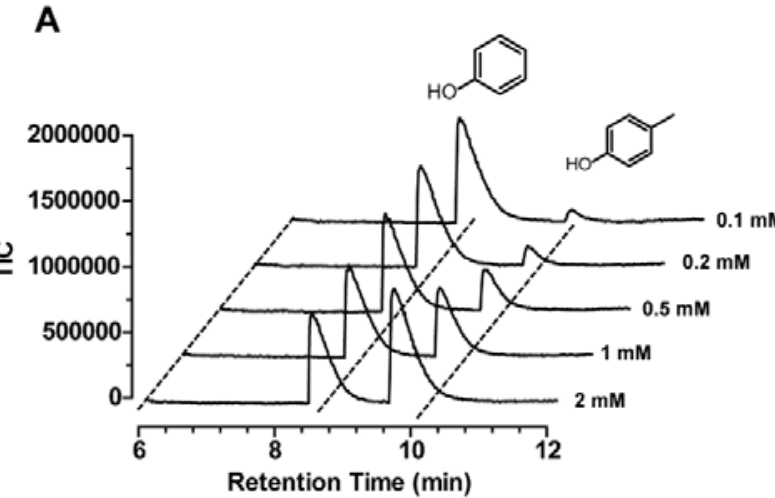

C

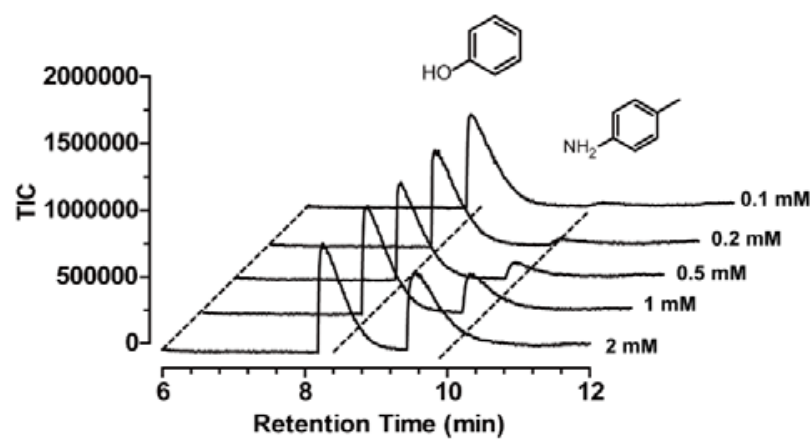

B

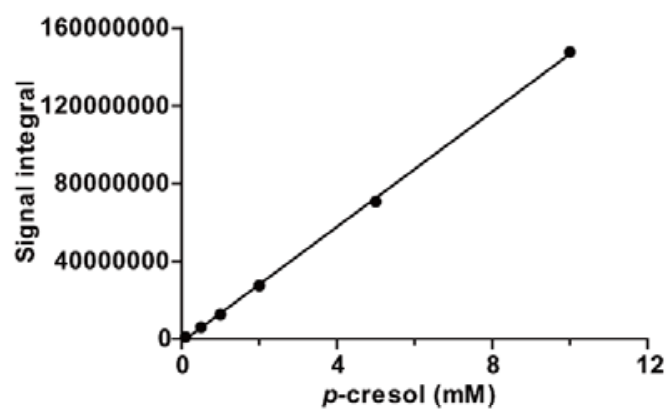

D

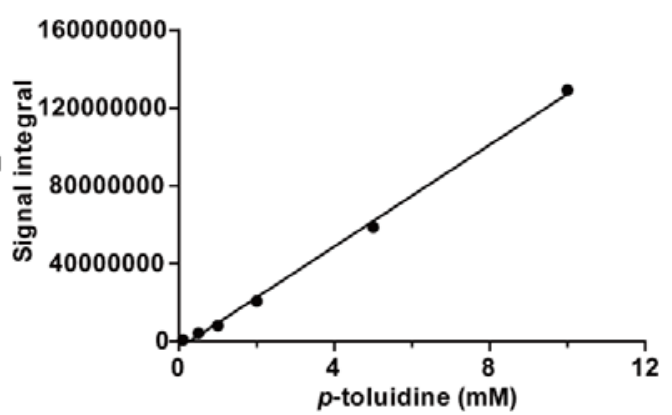

Figure S4. Establishment of $\boldsymbol{p}$-cresol and $\boldsymbol{p}$-toluidine standard curves. A. GC-MS traces of serial diluted $p$-cresol. B. The standard curve derived from A. C. GC-MS traces of serial diluted $p$-toluidine. D. The standard curve derived from C. $2.0 \mathrm{mM}$ phenol was used as internal standard to calibrate the machine. 
A

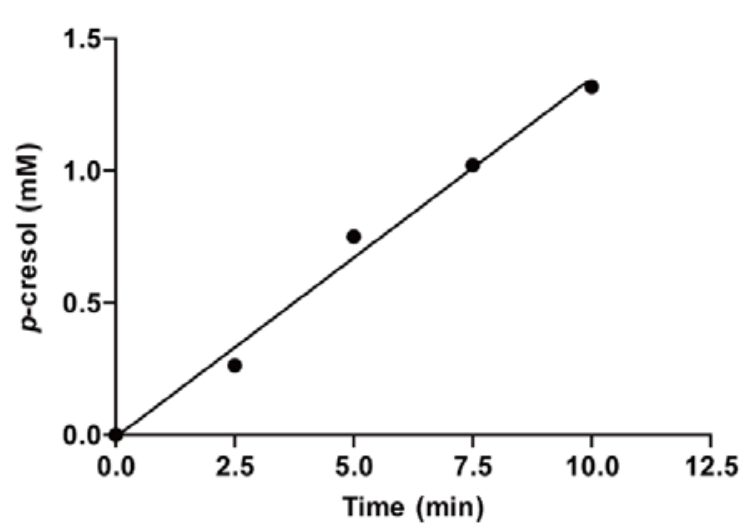

B

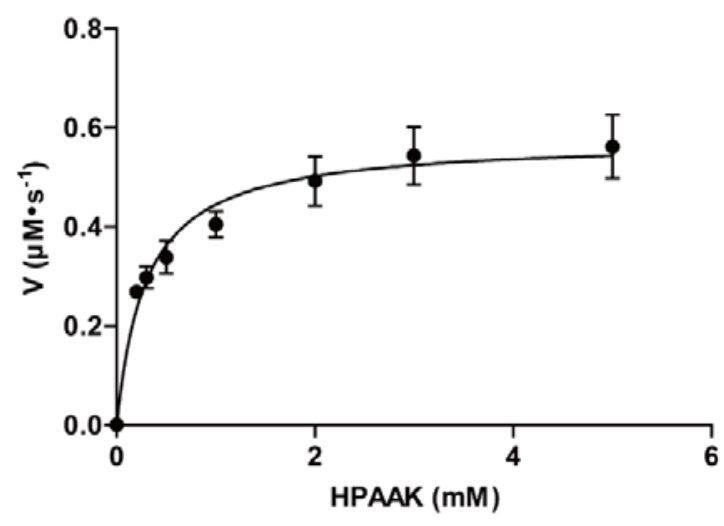

Figure S5. Kinetic assays for AAD measuring p-cresol formation by GC-MS. A. Timedependent $p$-cresol formation. $200 \mathrm{nM}$ AAD was assayed for activity with $10 \mathrm{mM}$ HPA. B. Michaelis-Menten kinetics of AAD. $50 \mathrm{nM}$ AAD was assayed for activity with varying HPA concentrations. The error bars represent the standard deviation of three individual experiments. 
A

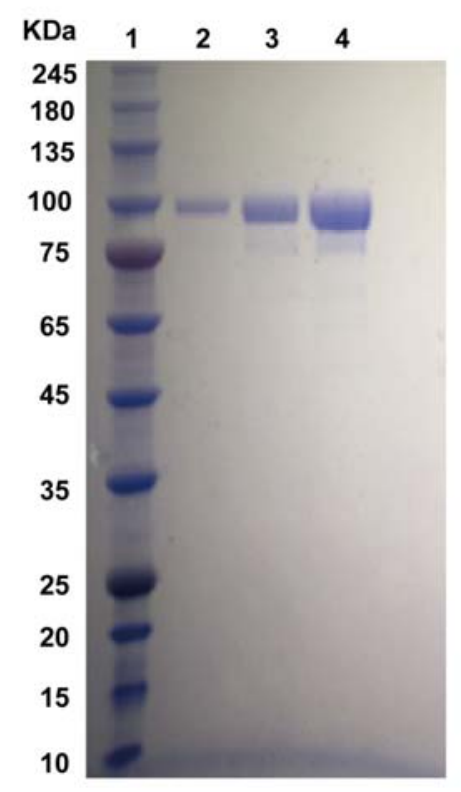

B

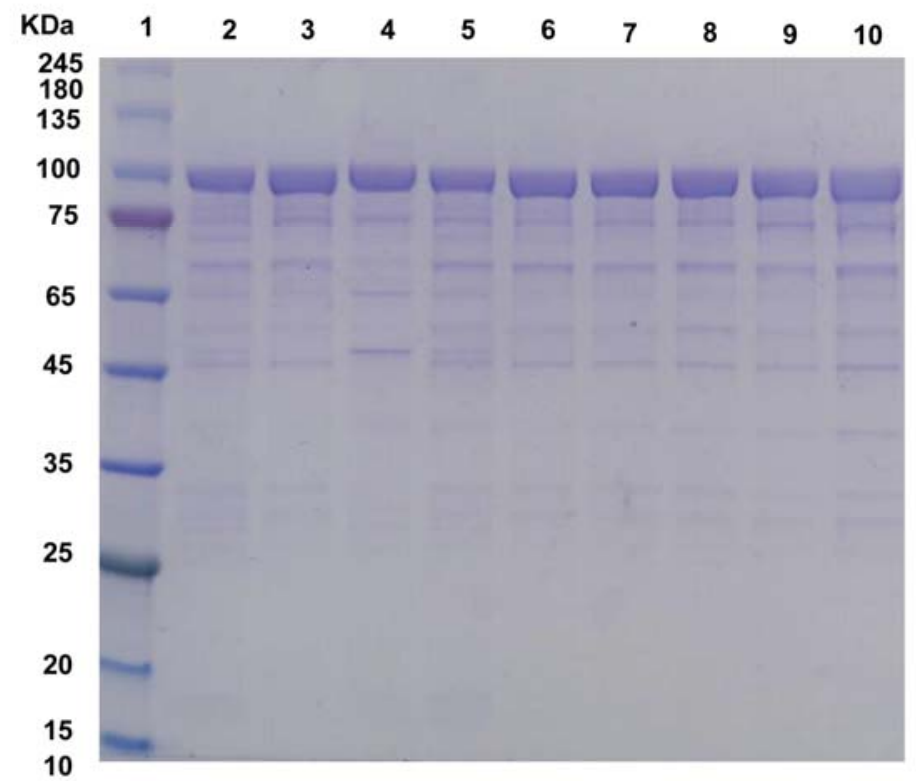

Figure S6. SDS-PAGE analyses of purified AAD for crystallization and mutant AADs. A. AAD used in crystal screen. 10\% SDS polyacrylamide gel with: lane 1, protein molecular weight marker; and lane 2-4: 1, 2, $4 \mu \mathrm{g}$ of AAD with His6-tag removed. B. Mutant His6tagged AADs. 10\% SDS polyacrylamide gel with: lane 1, protein molecular weight marker; and lane 2-10: S166A, K172A, W174F, Y291F, C447S, W460A, Y564F, H658N, and G782A respectively. 
A

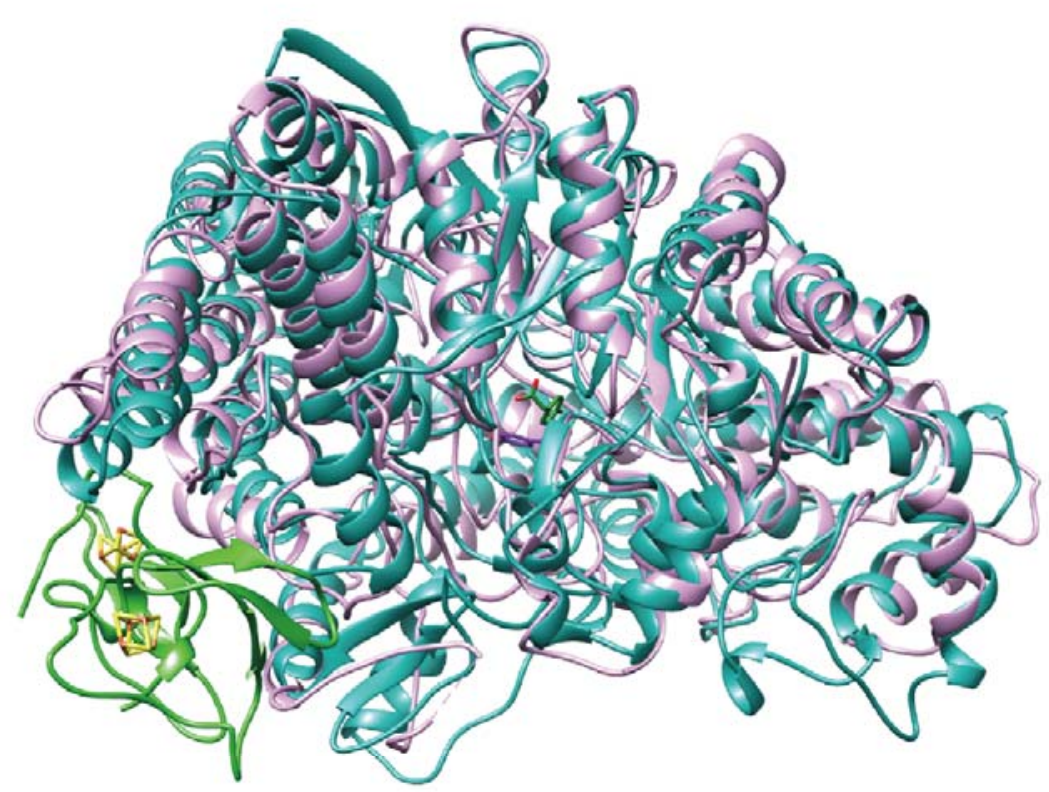

B

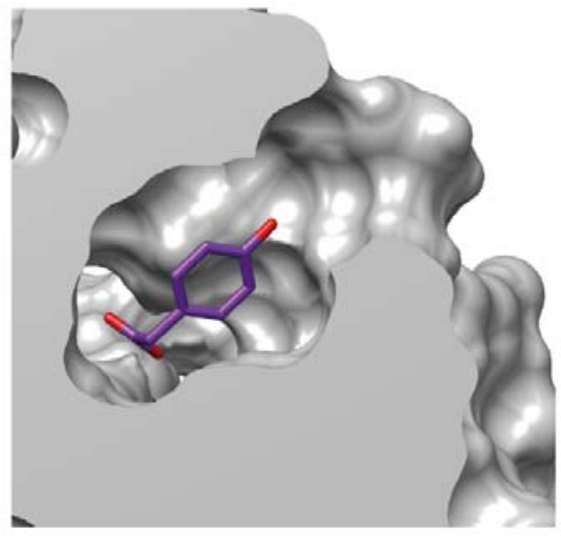

AAD surface (7E7L)

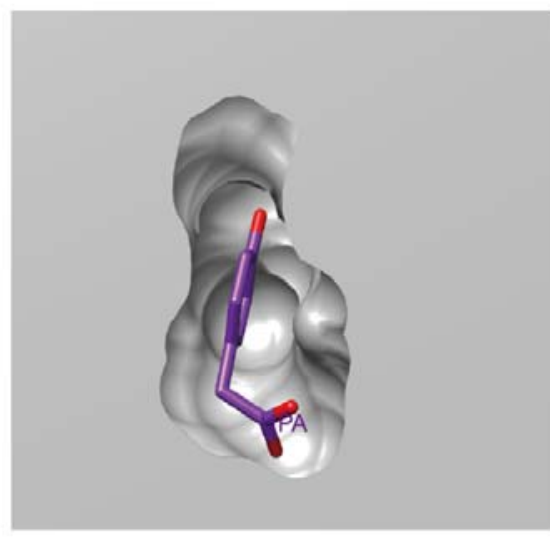

HPAD surface (2YAJ)

Figure S7. Comparison of AAD and HPAD crystal structures. A. Superposition of AAD crystal structure (plum) (PDB code 7E7L) with HPAD (light sea green, large subunit and light green, small subunit) (PDB code 2YAJ). B. Surface plot of the AAD and HPAD substrate binding pockets. The void volumes of AAD and HPAD were calculated to be 391 $\AA^{3}$ and $166 \AA^{3}$ respectively. 
A

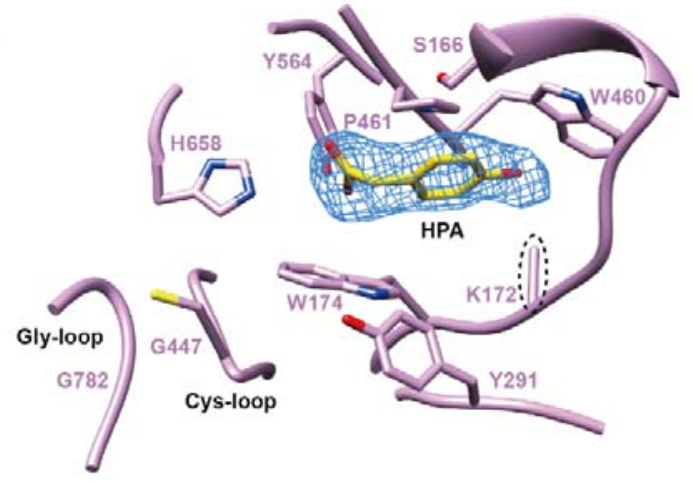

2Fo-Fc of substrate

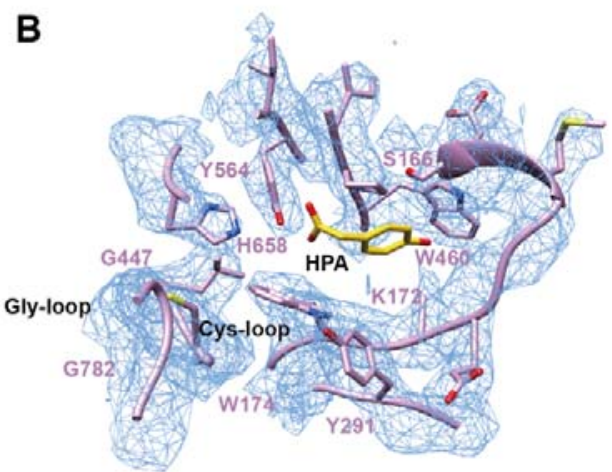

2Fo-Fc of side chain

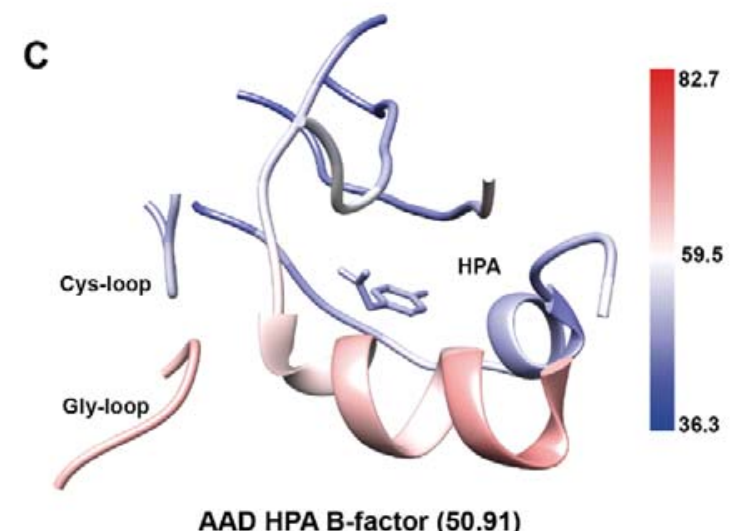

AAD HPA B-factor (50.91)

D

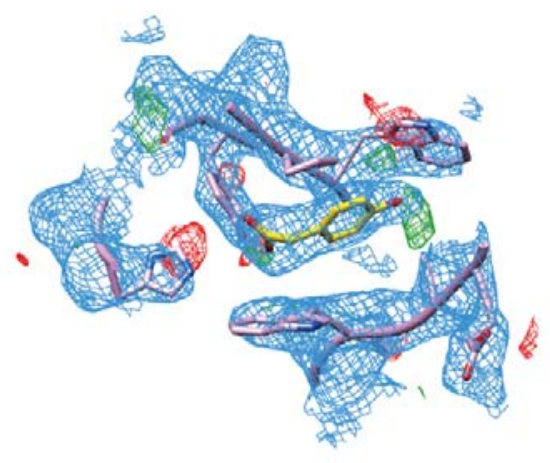

Fo-Fc (no Lys side chain)

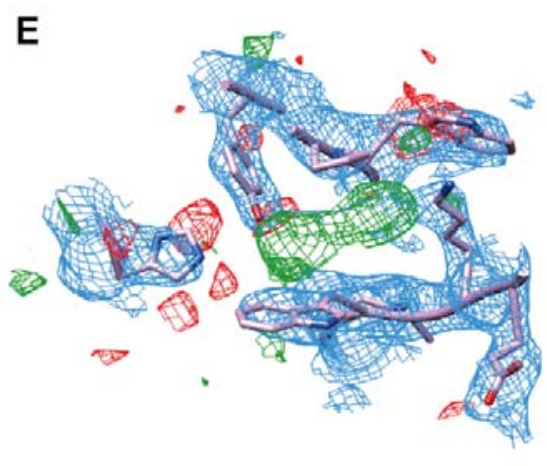

Fo-Fc (no substrate)

Figure S8. Structure of the AAD active site. A. and B. 2FoFc electron density map of HPA and of the surrounding active site residues is depicted in mesh and shown at $1.0 \sigma$. $\mathbf{C}$. Structure of AAD and some surrounding residues were colored according to B-factor values. D. and E. Fo-Fc maps for two models of AAD, omitting the side chain of Lys172 or omitting HPA. In the former, no clear difference density appeared, while in the latter, a strong positive difference density appeared at level of more than $5 \sigma$, demonstrating that the density originates from the bound HPA. 


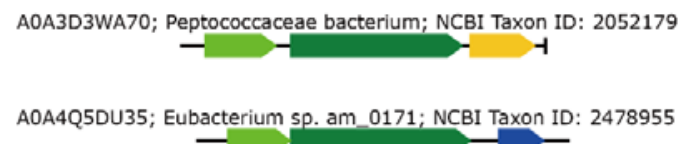

A0A4Q5DU35; Eubacterium Sp. am_0171; NCBI Taxon ID: 2478955

Q30WU7; Desulfovibrio alaskensis (strain G20); NCBI Taxon ID: 207559

Query UniProt ID: A0A174FP99; Faecalicatena contorta; NCBI Taxon ID: 39482

- A -

A0A3E2WWB3; Hungatella hathewayi; NCBI Taxon ID: 154046

A0A100YWM3; Olsenella scatoligenes; NCBI Taxon ID: 1299998

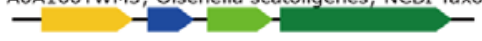

A0A154BWA2; Anaerosporomusa subterranea; NCBI Taxon ID: 1794912

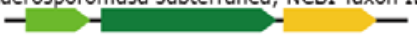

A0A1C5VK14; uncultured Roseburia sp; NCBI Taxon ID: 512314

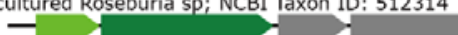

A0A3A6NKJ3; Dethiobacter SP; NCBI Taxon ID: 2093370

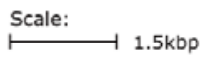

B

Organism

Percentage identity $(\%)$

$\begin{array}{llllllllll}\text { Desulfovibrio alaskensis } & 100 & 86 & 59 & 67 & 62 & 62 & 62 & 47 & 41\end{array}$

$\begin{array}{llllllllll}\text { Anaerosporomusa subterranea } & 86 & 100 & 60 & 68 & 63 & 62 & 63 & 46 & 40\end{array}$

Olsenella scatoligenes

$\begin{array}{lllllllll}59 & 60 & 100 & 65 & 70 & 69 & 69 & 47 & 42\end{array}$

Peptococcaceae bacterium

$\begin{array}{lllllllll}67 & 68 & 65 & 100 & 70 & 70 & 70 & 47 & 43\end{array}$

Hungatella hathewayi

$\begin{array}{lllllllll}62 & 63 & 70 & 70 & 100 & 98 & 97 & 48 & 44\end{array}$

Eubacterium $s p$

Faecalicatena contorta

$\begin{array}{lllllllll}62 & 62 & 69 & 70 & 98 & 100 & 100 & 48 & 43\end{array}$

Roseburia sp.

$\begin{array}{lllllllll}62 & 63 & 69 & 70 & 97 & 100 & 100 & 48 & 43\end{array}$

Dethiobacter sp.

C

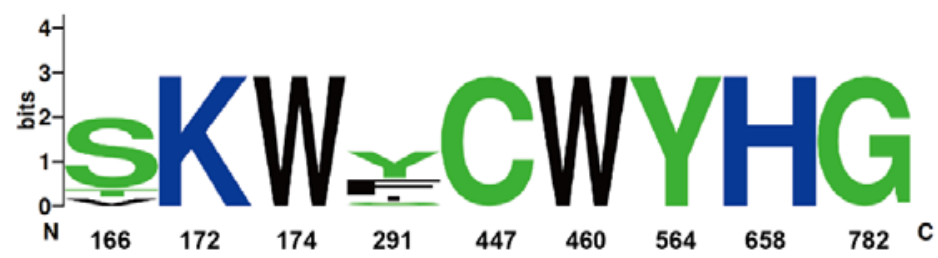

Figure S9. Close homologs of AAD in different bacteria. A. Genome neighborhoods of AAD homologs in different bacteria. UniProt accession numbers, organism name and taxonomic identifier are given. Dark green, AAD; light green, AAD-AE; yellow, MFS transporter; blue, transcriptional regulator; red, tripartite ATP-independent periplasmic (TRAP) transporter substrate-binding unit. B. Sequence identity matrix of AAD homologs. C. Sequence logo showing the conservation for radical-bearing and substrate-interacting residues in close homologs of $O$. scatoligenes AAD. 


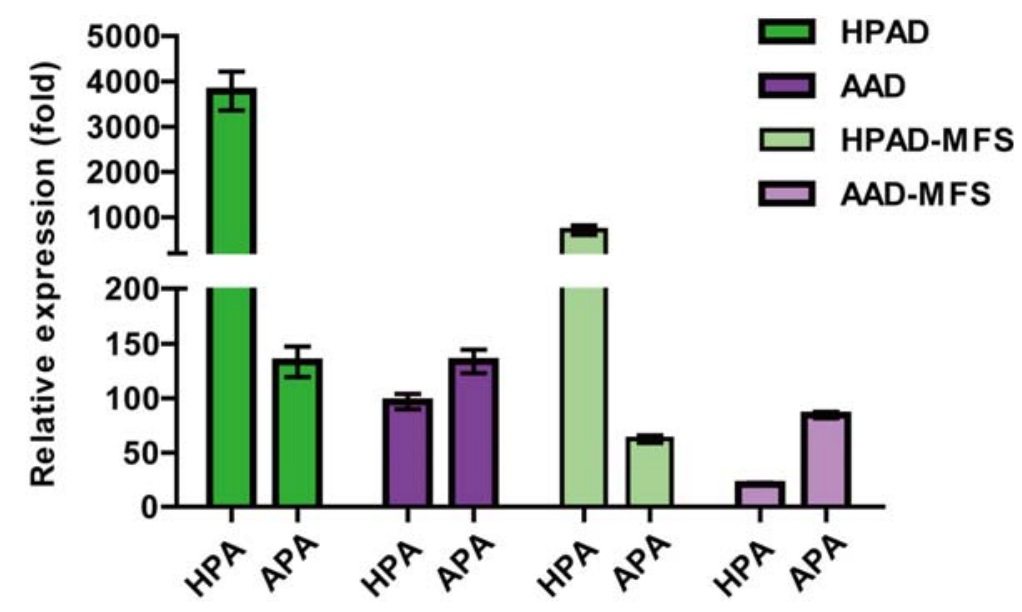

Figure S10. qPCR analyses of the transcription levels of AAD, HPAD and their related transporters. The transcriptional levels of genes of interest were normalized by that of the $16 \mathrm{~S}$ rRNA. The induction by HPA and APA were displayed in comparison with the transcriptional data from glucose-grown cells. Bars in different colors were as indicated. 

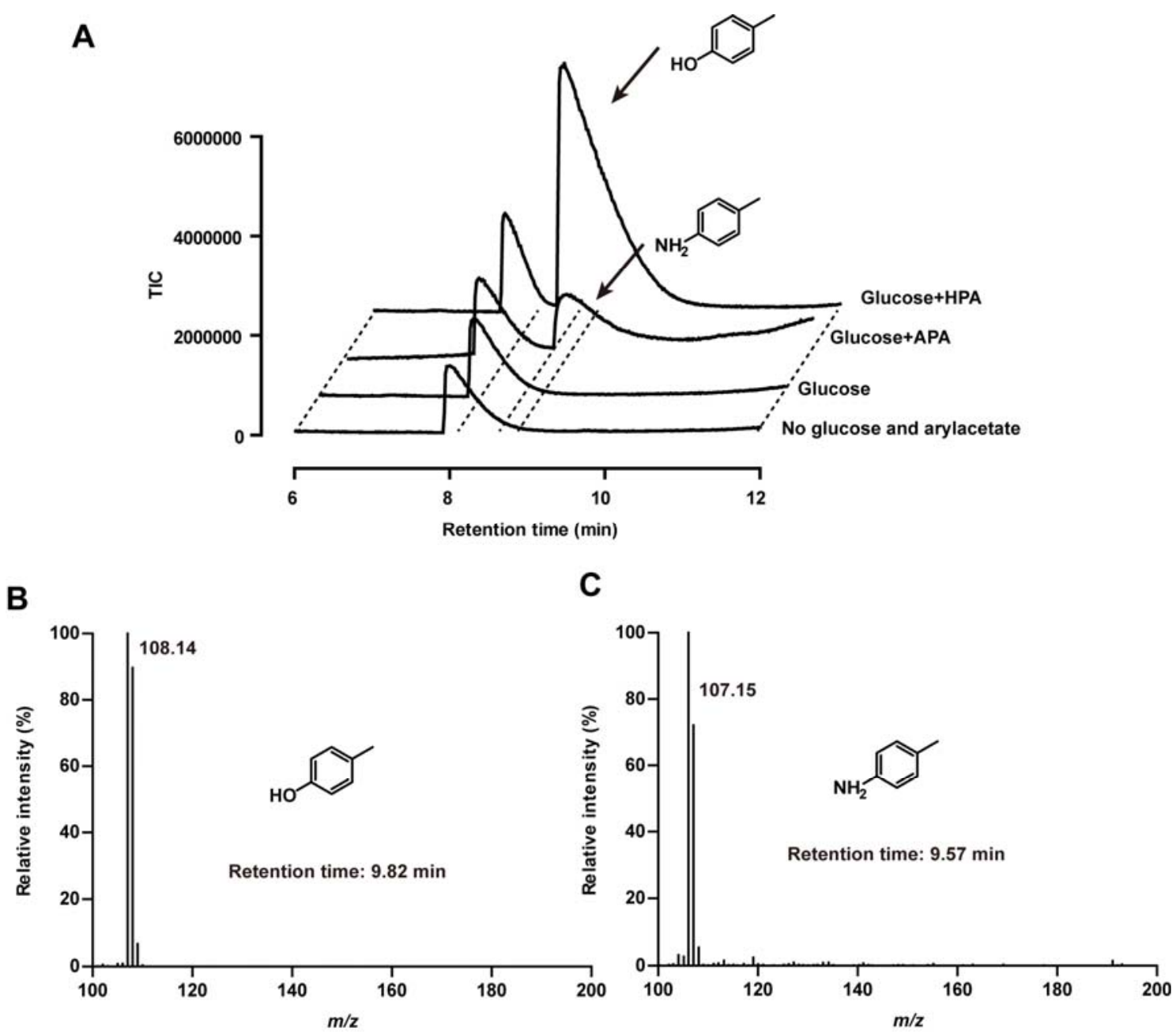

Figure S11. GC-MS confirmed the production of $p$-cresol and $p$-toluidine in the HPAand APA-containing growths respectively. A. GC-MS elution profiles of each sample contained phenol as an internal standard. B. Mass spectra of the product peaks, indicated by arrows in A. C. Mass spectra of the product peaks, indicated by arrows in $\mathbf{A}$. 


\section{References}

1. fish, W. W., [27] Rapid colorimetric micromethod for the quantitation of complexed iron in biological samples. In Methods in Enzymology, Academic Press: 1988; Vol. 158, pp 357-364.

2. (a) Siegel, L. M., A direct microdetermination for sulfide. Analytical biochemistry 1965, 11 (1), 126-132; (b) Zhang, Y.; Lyver, E. R.; Nakamaru-Ogiso, E.; Yoon, H.; Amutha, B.; Lee, D.-W.; Bi, E.; Ohnishi, T.; Daldal, F.; Pain, D., Dre2, a conserved eukaryotic Fe/S cluster protein, functions in cytosolic Fe/S protein biogenesis. Molecular and cellular biology 2008, 28 (18), 5569-5582.

3. Kelley, L. A.; Mezulis, S.; Yates, C. M.; Wass, M. N.; Sternberg, M. J., The Phyre2 web portal for protein modeling, prediction and analysis. Nature protocols 2015, 10 (6), 845-858.

4. Emsley, P.; Cowtan, K., Coot: model-building tools for molecular graphics. Acta crystallographica section D: biological crystallography 2004, 60 (12), 2126-2132.

5. Adams, P. D.; Afonine, P. V.; Bunkóczi, G.; Chen, V. B.; Davis, I. W.; Echols, N.; Headd, J. J.; Hung, L.-W.; Kapral, G. J.; Grosse-Kunstleve, R. W., PHENIX: a comprehensive Python-based system for macromolecular structure solution. Acta Crystallographica Section D: Biological Crystallography 2010, 66 (2), 213-221.

6. Edgar, R. C., MUSCLE: a multiple sequence alignment method with reduced time and space complexity. BMC Bioinformatics 2004, 5, 113.

7. Crooks, G. E.; Hon, G.; Chandonia, J. M.; Brenner, S. E., WebLogo: a sequence logo generator. Genome Res 2004, 14 (6), 1188-90. 